\title{
The prognostic value of pretreatment Glasgow Prognostic Score in patients with esophageal cancer: a meta-analysis
}

This article was published in the following Dove Press journal: Cancer Management and Research

\section{Yan Wang* \\ Pengfei $\mathrm{Li}^{*}$ \\ Jue Li \\ Yutian Lai \\ Kun Zhou \\ Xin Wang \\ Guowei Che}

Department of Thoracic Surgery, West China Hospital, Sichuan University, Chengdu 6I004I, People's Republic of China

*These authors contributed equally to this work
Correspondence: Guowei Che Department of Thoracic Surgery, West China Hospital, Sichuan University, Guoxuexiang No. 37, Chengdu, People's Republic of China

Tel +862818980601890

Fax +862885422494

Email cheguowei_hx@aliyun.com
Objectives: To examine the predictive role of Glasgow Prognostic Score (GPS) on longterm survival in esophageal cancer.

Method: Comprehensive searches of electronic databases were performed to identify potential studies that evaluated the prognostic value of pretreatment GPS in esophageal cancer patients. We combined the hazard ratios (HRs) with $95 \%$ confidence intervals (CIs) to assess the association of GPS with overall survival (OS), disease-free survival (DFS) and cancer-specific survival (CSS).

Results: A total of 21 studies including 6115 patients were analyzed. Compared with patients with GPS 0, patients with elevated GPS had poorer OS (HR $=2.12,95 \%$ CI: $1.83-2.45, P<0.001)$ and $\operatorname{CSS}(\mathrm{HR}=2.16,95 \% \mathrm{CI}: 1.56-2.98, P<0.001)$; but no significant relationship was observed between the elevated GPS and DFS (HR=2.14, 95\% CI:1.00-4.61, $P=0.051)$. Subgroup analysis outcomes were similar to overall analyses.

Conclusion: Pretreatment GPS could serve as a valuable factor in predicting the prognosis of patients with esophageal cancer. More well-designed prospective studies are warranted to confirm our findings.

Keywords: esophageal cancer, Glasgow Prognostic Score, survival, meta-analysis

\section{Introduction}

Esophageal cancer is the third most common malignant tumor and the fourth cause of cancer-related mortality in China. ${ }^{1}$ Esophageal cancer mainly comprises two pathology subtypes, esophageal squamous-cell carcinoma (ESCC) and esophageal adenocarcinoma (EAC). Despite of the advances in detection and treatment of esophageal cancer, its prognosis remains poor because patients were often diagnosed with the advanced stage. An ideal method that could predict the prognosis of esophageal cancer would be of great clinical significance.

A number of studies have reported that systemic inflammatory response is significantly associated with the prognosis of several kinds of cancers. ${ }^{2}$ Inflammatory factors including Glasgow Prognostic Score (GPS) have been proven to play an important role in tumor progression and metastasis. ${ }^{3-6}$ As an easily obtained inflammatory factor based on the serum C-reactive protein (CRP) and albumin levels, GPS was put forward in 2003 by Forrest et al for the first time and has been demonstrated to be predictors in the long-term survival of several neoplasms including gastric cancer, colorectal cancer, hepatocellular carcinoma, non-small cell lung cancer and 
esophageal cancer. ${ }^{7-11}$ The GPS was calculated as: a score of 0 for normal CRP $(<10.0 \mathrm{mg} / \mathrm{L})$ and albumin $(>35.0 \mathrm{~g} / \mathrm{L})$ levels, 1 for either an abnormal CRP $(>10.0 \mathrm{mg} / \mathrm{L})$ or abnormal albumin level $(<35.0 \mathrm{~g} / \mathrm{L})$ and 2 for both abnormal CRP $(>10.0 \mathrm{mg} / \mathrm{L})$ and abnormal albumin $(<35.0 \mathrm{~g} / \mathrm{L})$ levels. ${ }^{11}$

The role of pretreatment GPS on survival outcomes of esophageal cancer has also been explored by several studies, however, no consensus has been reached. To our knowledge, there exists no meta-analysis to confirm the value of GPS in predicting prognosis of esophageal cancer. Thus, the aim of our study was to provide a synthetic analysis of the role of GPS in esophageal cancer and to verify the prognostic significance and clinical relevance of GPS in esophageal cancer patients.

In this study, we evaluated the predictive value of pretreatment GPS for overall survival (OS), disease-free survival (DFS) and cancer-specific survival (CSS) in patients with esophageal cancer by pooling the available data.

\section{Methods}

\section{Search strategy}

A systematic search was performed in PubMed, the Cochrane Library, EMBASE (via OVID) and Web of Science from January 1, 1966 to October 31, 2018 to identify potential studies that explored the prognostic role of GPS in esophageal cancer.

The search strategy used both with MeSH terms and free-text words to increase sensitivity. The following search terms were used: "esophagus", "esophageal", "cancer", "carcinoma", "tumor", "neoplasm", "Glasgow prognostic score", "GPS", "C-reactive protein" and "serum albumin". Moreover, the references cited in the included articles were explored for additional publications.

We evaluated all searched results according to the Preferred Reporting Items for Systematic Reviews and Meta-Analyses (PRISMA) statement. The publication language was limited to English. We screened titles and abstracts to identify related studies, and then full texts were evaluated carefully.

\section{Inclusion and exclusion criteria}

The following inclusion criteria were used: (1) articles investigating the relation of GPS and prognosis for esophageal cancer patients; (2) C-reactive protein and serum albumin levels were collected before any treatment such as the chemoradiotherapy, surgery and neoadjuvant chemoradiotherapy; (3) full text papers published in English; (4) the outcome of interest included OS, DFS or CSS with hazards ratios (HRs) and corresponding 95\% confidence intervals (CIs).

The following exclusion criteria were used: (1) letters, editorials, expert opinions, case reports, and reviews; (2) nonhuman studies; (3) if data sets were duplicated or overlapped, only the most recent information was included.

\section{Data collection}

Data were extracted by two researchers (Yan Wang and Pengfei Li) independently. Any disagreement was resolved through team discussion until consensus reached. Data were retrieved from each article by using an excel sheet (Microsoft Corporation). The following information was extracted from all included studies: the first author of the study, publication year, country, study period, study design, number of patients, female-male ratio, pathology type, treatment, follow up period, tumor-node-metastasis (TNM) stage and HR with $95 \%$ confidence interval (CI) of each long-term outcome.

We calculated the pooled HRs from each study in multivariate models whenever available if no multivariate statistic was reported then HRs from univariate analyses were used. HRs would be calculated from the KaplanMeier curves according to the methods reported by Tierney et al if they could not be obtained directly from the articles. ${ }^{12}$ The first author and the publication year were used for identification.

\section{Statistical analyses}

For each study, the HR with $95 \%$ CI was used to estimate the prognostic value of GPS on the long-term survival of esophagus cancer patients. If groups comparing GPS 2 with 0 and 1 with 0 were both reported then the former one was used for synthesis in the forest plot. Statistical heterogeneity between studies was evaluated using Cochran's Q test and Higgins $\mathrm{I}^{2}$ statistic; and significant heterogeneity was defined as $P<0.10$ and/or $\mathrm{I}^{2}>50 \% .{ }^{13}$ The random-effects model was used to calculate the pooled effect estimates when significant heterogeneity was observed, otherwise the fixed-effects model was applied. The robustness of the pooled results was confirmed by a sensitivity analysis in which the data of an individual study was removed each time. Publication bias was evaluated by Begg's funnel plot and Egger's linear regression 
tests. When publication bias was observed presenting a $P<0.05$, the nonparametric trim and fill method was applied to re-estimate a corrected effect size after adjustment for publication bias. ${ }^{14}$ All analyses were performed according to the PRISMA guidelines and by STATA (version 12.0; Stata Corporation). ${ }^{15}$

\section{Quality assessment}

The quality of the included studies was assessed with the NOS (Newcastle-Ottawa quality assessment scale). Studies earned a score of 6 or higher were regarded as high-quality studies. Quality assessment was conducted by two independent researchers (Yutian Lai and Kun Zhou).

\section{Results}

\section{Literature selection process}

The initial searching yielded 481 records from the four electronic databases, with no additional publications discovered. After duplicates removed, a total of 215 records were screened. Finally, 21 studies investigating the prognostic role of GPS in esophageal cancer patients met our criteria and were enrolled. ${ }^{4-6,11,16-32}$ (Figure 1)

\section{Characteristics of included studies}

The characteristics of these 21 studies were summarized in Table 1. The majority of the studies were from Asian countries. All of the studies were retrospective observational studies except for a randomized controlled trial (RCT) from Japan. The sample size ranged from 48 to 1135 patients. All enrolled patients received esophagectomy in 13 studies and in another 3 studies patients were treated with chemotherapy and radiotherapy, while patients in the remained 5 studies were treated with mixed therapies. Only one study did not provide the HR with $95 \%$ CI and the crude HR with 95\% CI was estimated from the corresponding Kaplan-Meier curve. These

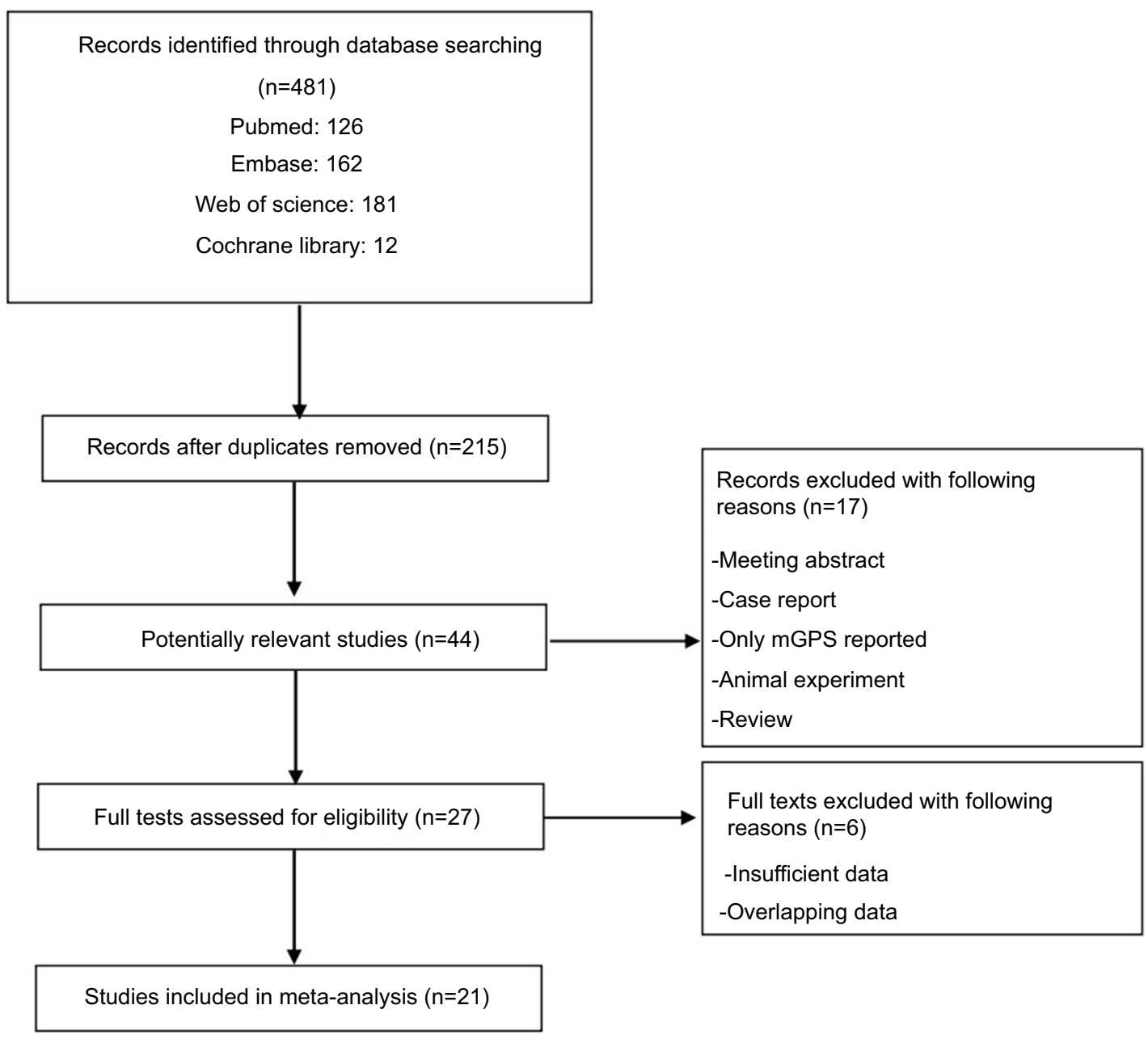

Figure I Flow diagram of the literature review. 


\begin{tabular}{|c|c|c|c|c|c|c|c|c|}
\hline 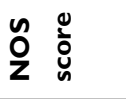 & 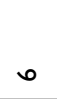 & 0006 & $00 \wedge \infty \wedge 6000$ & n & $\wedge \bullet \wedge \infty$ & $\bullet$ & n & 空 \\
\hline 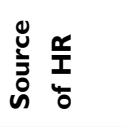 & $\simeq$ & $\propto \propto \propto \propto$ & $\propto \propto \propto \propto \propto ⿻ \propto ⿻ 上 丨 \propto ⿻ 上 丨$ & $\simeq$ & $\propto \propto \propto \propto ⿻ 上 丨$ & $\simeq$ & $\propto$ & 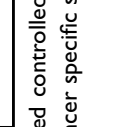 \\
\hline 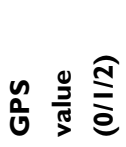 & 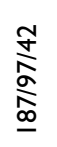 & 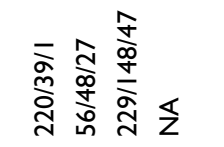 & 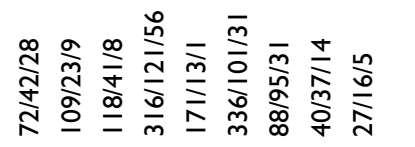 & 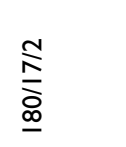 & 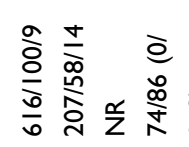 & 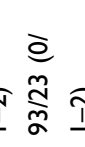 & 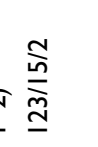 & 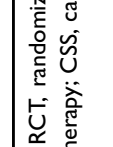 \\
\hline 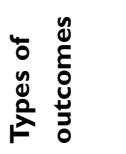 & $\tilde{U}$ & 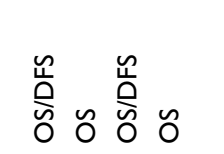 & 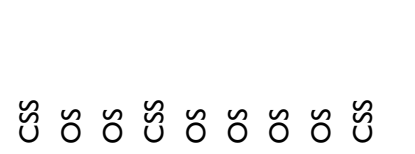 & 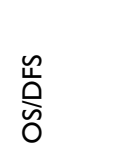 & 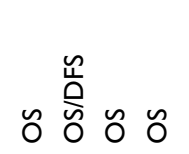 & oิ & 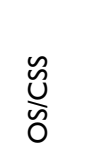 & 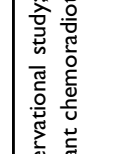 \\
\hline$\sum_{\mathbf{Z}}$ & 笔 & $\underset{i}{\geqq} \stackrel{\geqq}{=} \geqq$ & 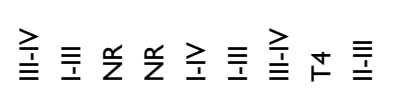 & $\geqq$ & 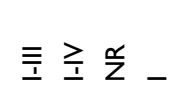 & $\geqq$ & $\geqq$ & 品 \\
\hline 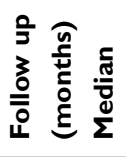 & 字 & 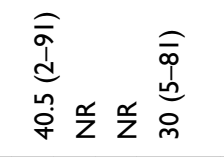 & 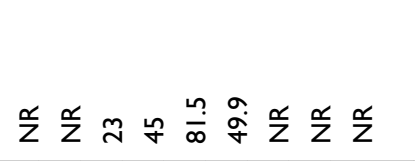 & $\stackrel{\substack{\infty \\
\infty}}{\infty}$ & $\stackrel{\infty}{\sim} \frac{o}{Z} \frac{o}{z} \frac{\infty}{x}$ & $\stackrel{m}{m}$ & $\stackrel{\circ}{\dot{m}}$ & రై \\
\hline 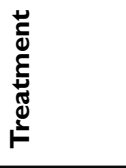 & $\begin{array}{l}\vec{E} \\
\pm \\
\pm \\
\vdots \\
\vdots\end{array}$ & 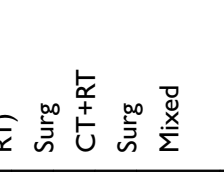 & 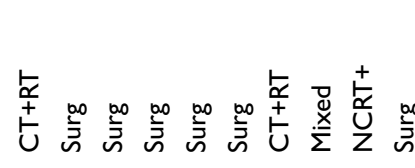 & 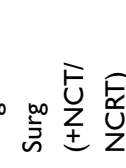 & 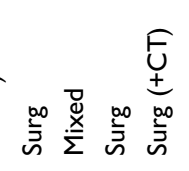 & $\begin{array}{l}\frac{\bar{d}}{\dot{x}} \\
\frac{\dot{x}}{\Sigma}\end{array}$ & 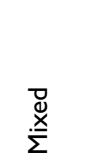 & 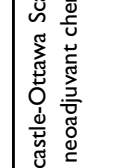 \\
\hline 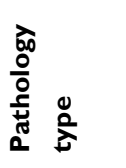 & U্ & 足 & 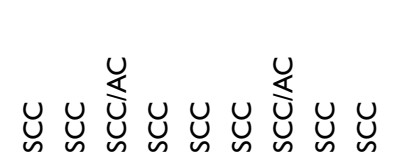 & 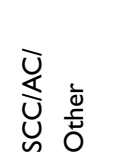 & 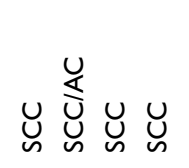 & U্ & 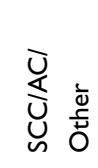 & 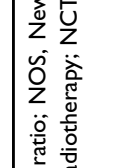 \\
\hline 离 & 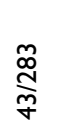 & 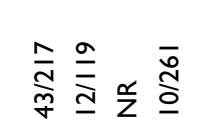 & 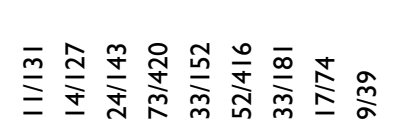 & $\frac{\infty}{2}$ & 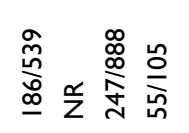 & $\stackrel{\infty}{\stackrel{\infty}{\infty}}$ & 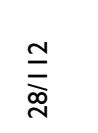 & 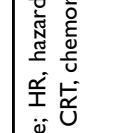 \\
\hline 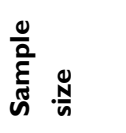 & 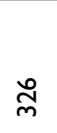 & 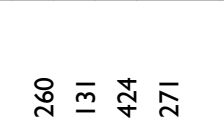 & 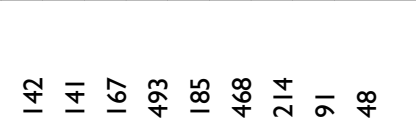 & $\underline{\sigma}$ & 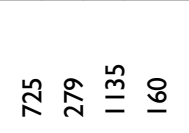 & $\stackrel{\varrho}{=}$ & q & \\
\hline 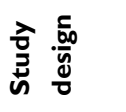 & ఝั & ô & ô ô & ơ & ఝั & ֻั & ֻั & \\
\hline 질 & 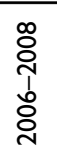 & 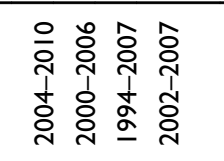 & 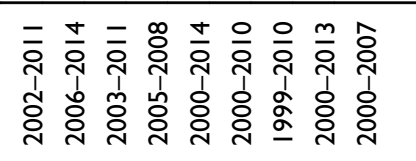 & 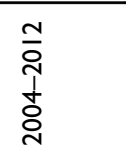 & 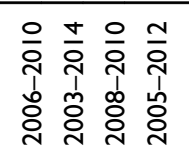 & 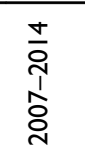 & 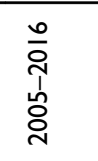 & 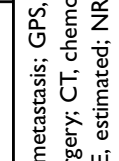 \\
\hline نे & 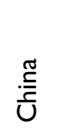 & 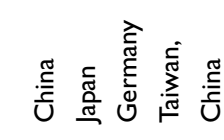 & 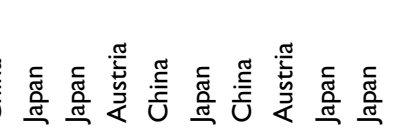 & 丞 & 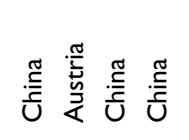 & 胥 & $\begin{array}{l}\text { 总 } \\
\text { 兽 }\end{array}$ & \\
\hline 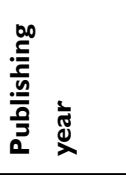 & $\stackrel{n}{\frac{n}{n}}$ & 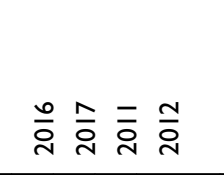 & 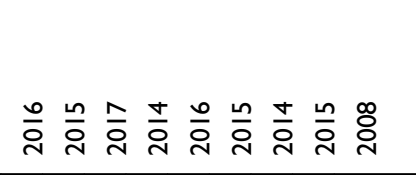 & $\frac{n}{2}$ & 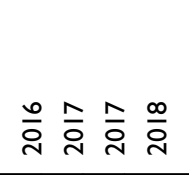 & $\overline{\mathrm{N}}$ & $\overline{\bar{i}}$ & 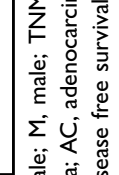 \\
\hline 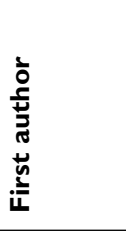 & & 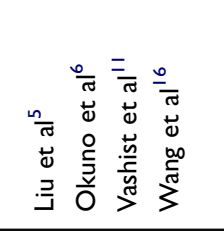 & 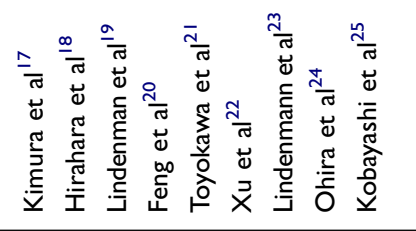 & 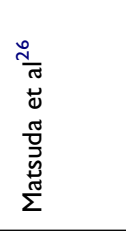 & 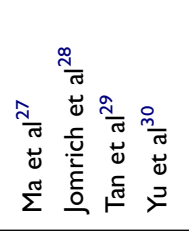 & 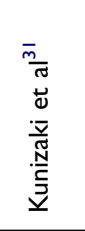 & 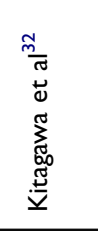 & 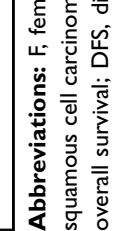 \\
\hline
\end{tabular}


articles were published between 2008 and 2018 and NOS scores of the included studies ranged from 6 to 8 which indicated that these studies were of high quality.

\section{Association of GPS with OS, DFS and CSS}

There were 17, 4 and 5 studies which reported the correlation of GPS with OS, DFS and CSS. The results demonstrated a significant relationship between elevated GPS and poor OS $(\mathrm{HR}=2.12,95 \% \mathrm{CI}: 1.83-2.45, P<0.001)$ with low heterogeneity $\left(\mathrm{I}^{2}=25.9 \%, P=0.159\right)$ (Figure 2 ) and poor CSS (HR $=2.16,95 \% \mathrm{CI}: 1.56-2.98, P<0.001)$ with high heterogeneity $\left(\mathrm{I}^{2}=73.2 \%, P=0.005\right)$ (Figure 3 ), but failed to show a significant correlation between GPS and DFS (HR $=2.14,95 \%$ CI: $1.00-4.61, P=0.051)$ with high heterogeneity $\left(\mathrm{I}^{2}=60.9 \%, P=0.053\right)$ (Figure 4 ).

\section{Subgroup analysis}

Patients with elevated GPS had a significantly worse OS compared with those with GPS 0. Subgroup analyses based on the ethnicity, sample size, pathology type, source of GPS, treatment and NOS score were performed to further explain our findings and the results manifested that none of these factors affected the prognostic role of GPS on OS. Detailed information was presented in Table 2.

\section{Sensitivity analysis}

The influence of every single study on the combined HRs was evaluated by excluding each study individually from the meta-analysis. The results showed that the pooled HRs for OS were robust in our study. No significant deviation from the overall results was detected (Figure 5).

\section{Publication bias}

Begg's funnel plot and Egger's test were performed to evaluate the publication bias of included studies presenting the association of GPS with OS. The funnel plot was symmetric $(P=0.711$, Figure 6$)$ and no substantial publication bias was detected in the Egger's test $(P=0.553)$.

\section{Discussion}

The significant role of systemic inflammatory response in the genesis, development, and progression of malignancies has

\begin{tabular}{|c|c|c|c|}
\hline Study & & & $\%$ \\
\hline ID & & $\mathrm{HR}(95 \% \mathrm{Cl})$ & Weight \\
\hline Vashist (2011) & $\rightarrow$ & $2.50(1.70,3.60)$ & 14.97 \\
\hline Wang (2012) & & $2.00(0.69,5.77)$ & 1.87 \\
\hline Lindenmann (2014) & & $4.06(2.46,6.73)$ & 8.32 \\
\hline Hirahara (2015) & - & $2.05(1.03,3.93)$ & 4.72 \\
\hline Xu (2015) & $\rightarrow$ & $1.83(1.18,2.86)$ & 10.76 \\
\hline Ohira (2015) & $\rightarrow-$ & $2.15(1.17,3.97)$ & 5.63 \\
\hline Matsuda (2015) & 1 & $0.97(0.12,7.67)$ & 0.49 \\
\hline Liu (2016) & & $6.00(0.79,45.72)$ & 0.51 \\
\hline Toyokawa (2016) & & $1.02(0.47,2.24)$ & 3.40 \\
\hline Ma (2016) & $\rightarrow$ & $1.63(1.15,2.29)$ & 18.09 \\
\hline Okuno (2017) & & $1.95(1.19,3.18)$ & 8.73 \\
\hline Lindenman (2017) & & $2.17(1.28,3.69)$ & 7.52 \\
\hline Jomrich (2017) & + & $1.17(0.52,2.60)$ & 3.25 \\
\hline Kunizaki (2017) & $\longrightarrow$ & $2.64(1.39,5.24)$ & 4.77 \\
\hline kitagawa (2017) & $\frac{1}{10}$ & $3.23(1.52,6.44)$ & 4.03 \\
\hline $\operatorname{Tan}(2017)$ & + & $2.08(0.83,5.20)$ & 2.51 \\
\hline Yu (2018) & $i$ & $14.71(1.61,142.86)$ & 0.42 \\
\hline Overall $(I$-squared $=25.9 \%, P=0.157)$ & $\diamond$ & $2.12(1.83,2.45)$ & 100.00 \\
\hline .007 & & 43 & \\
\hline
\end{tabular}

Figure 2 Forest plot of the association between GPS and overall survival. 


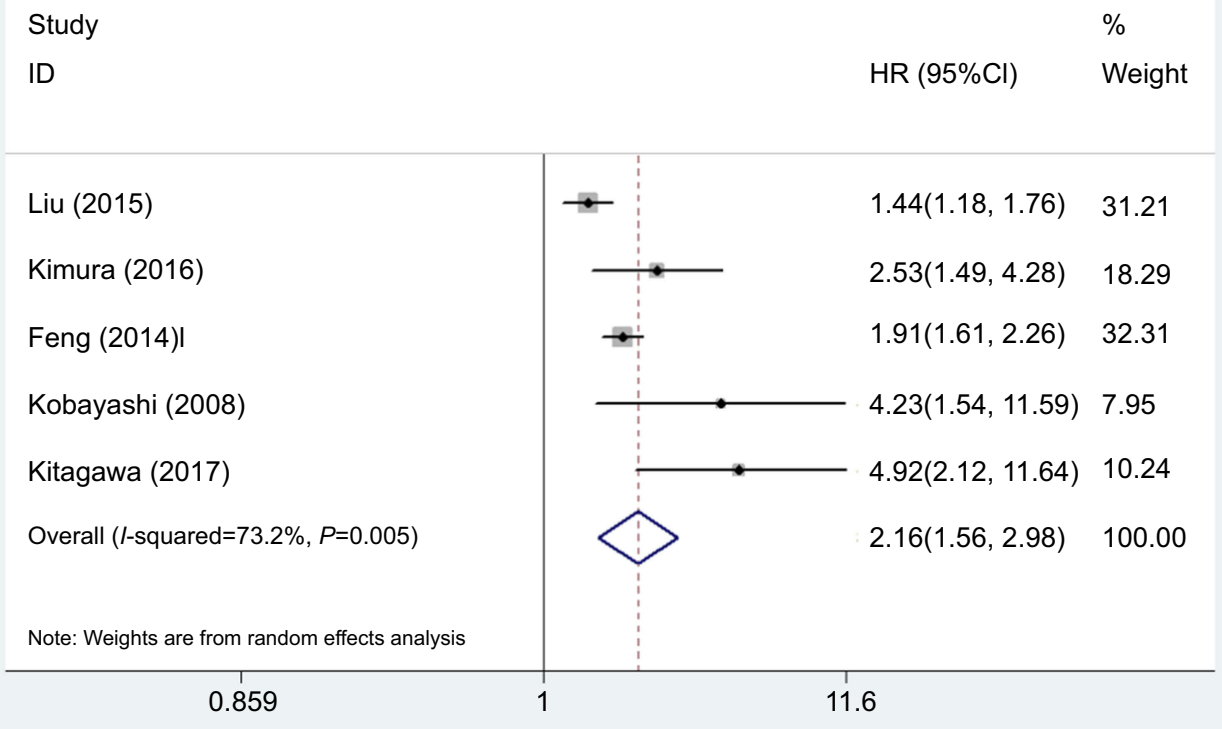

Figure 3 Forest plot of the association between GPS and cancer-specific survival.

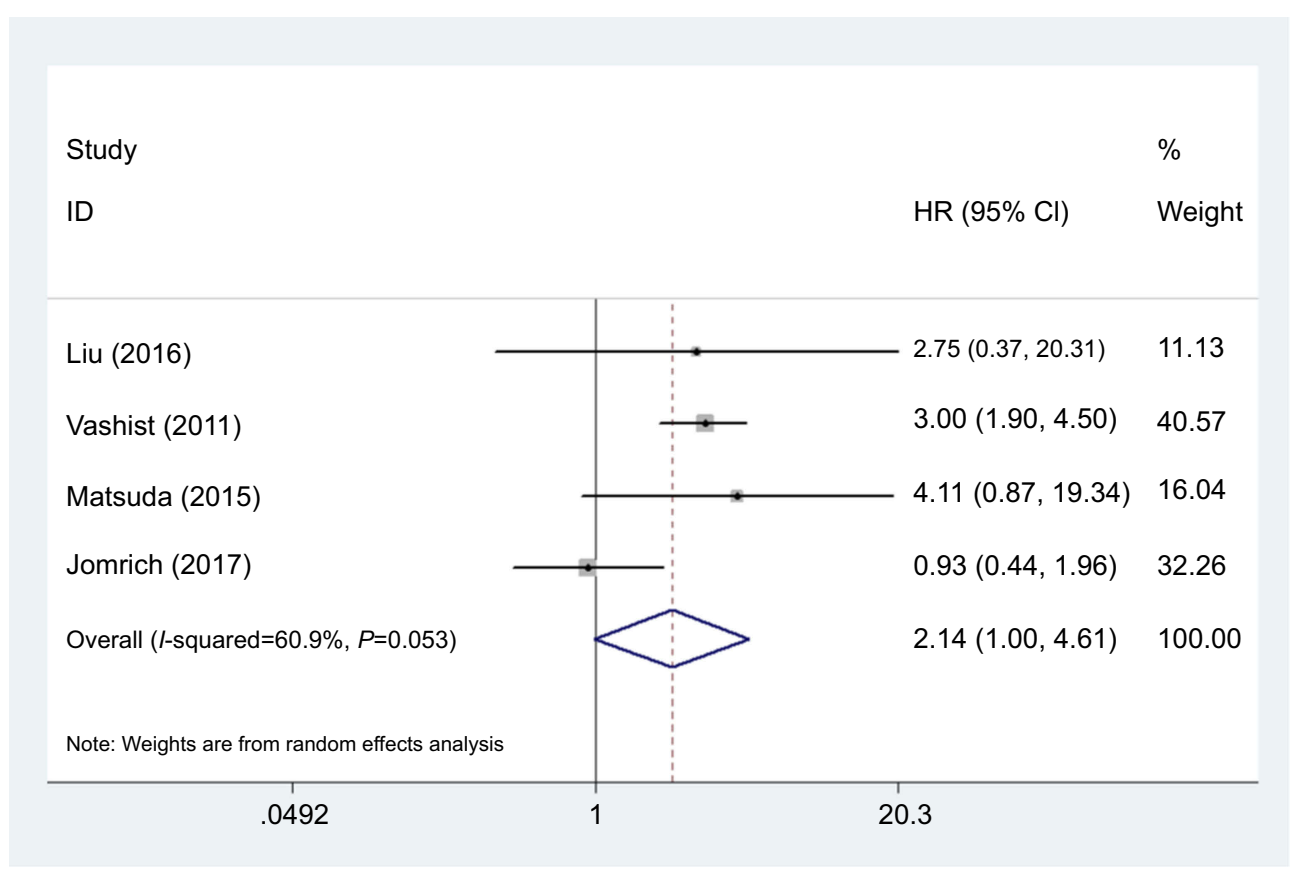

Figure 4 Forest plot of the association between GPS and disease-free survival.

been identified and verified. ${ }^{2-7}$ GPS is an easily obtained inflammation-based score which combines serum CRP and albumin. During the past decade, increasing studies have investigated the prognostic role of GPS in several solid cancers like lung cancer, liver cancer, as well as esophageal cancer. $^{7,9,11}$ Most of the studies about esophageal cancer demonstrated that the elevated GPS was significantly associated with poor long-term survival. ${ }^{16-32}$ However, the sample sizes of these studies were relatively small and the results were inconsistent with each other. Therefore, we designed the current research to further verify the prognostic value of GPS in esophageal cancer patients. Our meta-analysis, 
Table 2 Summary of HRs for the overall and subgroup analyses of GPS and esophageal cancer

\begin{tabular}{|c|c|c|c|c|c|}
\hline Analysis & & No. of studies & HR (95\% CI) & $P$-value & $I^{2}(\%)$ \\
\hline Overall survival & & 17 & $2.12(1.83-2.45)$ & $<0.001$ & 25.9 \\
\hline Ethnic & $\begin{array}{l}\text { China } \\
\text { Japan }\end{array}$ & $\begin{array}{l}6 \\
7\end{array}$ & $\begin{array}{l}1.84(1.41-2.39) \\
2.06(1.59-2.66)\end{array}$ & $\begin{array}{l}<0.001 \\
<0.001\end{array}$ & $\begin{array}{l}3.8 \\
0.0\end{array}$ \\
\hline Sample size & $\begin{array}{l}\text { Non-Asian } \\
\geq 200 \\
<200\end{array}$ & $\begin{array}{l}4 \\
8 \\
9\end{array}$ & $\begin{array}{l}2.42(1.61-3.65) \\
2.12(1.76-2.55) \\
2.12(1.69-2.67)\end{array}$ & $\begin{array}{l}<0.001 \\
<0.001 \\
<0.001\end{array}$ & $\begin{array}{l}58.6 \\
46.2 \\
6.8\end{array}$ \\
\hline Pathology & $\begin{array}{l}\text { SCC } \\
\mathrm{SCC}+\mathrm{AC}+(\text { Other })\end{array}$ & $\begin{array}{l}10 \\
7\end{array}$ & $\begin{array}{l}1.87(1.55-2.26) \\
2.54(2.02-3.19)\end{array}$ & $\begin{array}{l}<0.001 \\
<0.001\end{array}$ & $\begin{array}{l}0.0 \\
31.1\end{array}$ \\
\hline Source of GPS & $\begin{array}{l}\text { GPS }=2 \\
G P S \geq 1\end{array}$ & $\begin{array}{l}7 \\
10\end{array}$ & $\begin{array}{l}2.30(1.86-2.84) \\
1.97(1.62-2.4 I)\end{array}$ & $\begin{array}{l}<0.001 \\
<0.001\end{array}$ & $\begin{array}{l}44.4 \\
7.8\end{array}$ \\
\hline Treatment & Surgery & 10 & $1.95(1.58-2.40)$ & $<0.001$ & 13.3 \\
\hline NOS & $\begin{array}{l}\text { Chemoradiotherapy } \\
\geq 7 \\
<7\end{array}$ & $\begin{array}{l}2 \\
7 \\
10\end{array}$ & $\begin{array}{l}2.81(1.37-5.76) \\
1.85(1.45-2.35) \\
2.29(1.91-2.75)\end{array}$ & $\begin{array}{l}0.005 \\
<0.001 \\
<0.001\end{array}$ & $\begin{array}{l}76.1 \\
34.1 \\
14.4\end{array}$ \\
\hline Cancer specific survival & & 5 & $2.16(1.56-2.98)$ & $<0.001$ & 73.2 \\
\hline Disease-free survival & & 4 & $2.14(I .00-4.6 I)$ & 0.051 & 60.9 \\
\hline
\end{tabular}

Abbreviations: HR, hazard ratio; GPS, Cl, confidence interval; Glasgow Prognostic Score; SCC, squamous cell carcinoma; AC, adenocarcinoma; NOS, Newcastle-Ottawa Scale.

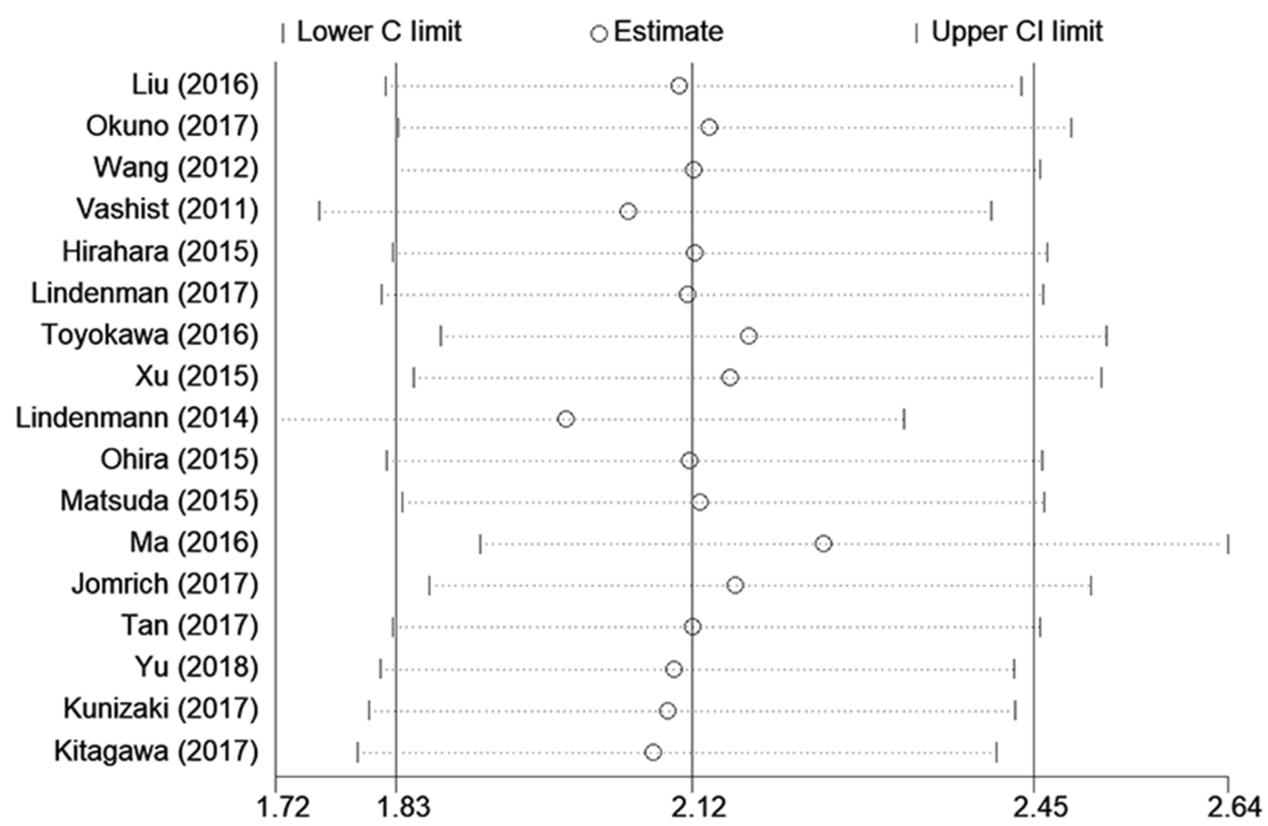

Figure 5 Sensitivity analysis of the association between GPS and overall survival.

including 21 studies, certified that the elevated GPS was associated with significantly poorer OS and CSS and the subgroup analyses based on the ethnicity, sample size, pathology, treatment and NOS score confirmed the strong connection between elevated GPS and worse OS in each subgroup.
As an acute phase protein, CRP has long been regarded as a marker of the inflammatory response, which is associated with cancer pathogenesis and progression. ${ }^{33} \mathrm{CRP}$ is a non-specific inflammatory factor and any disturbance such as neoadjuvant therapy could influence its level, so only studies in which GPS were obtained before any 


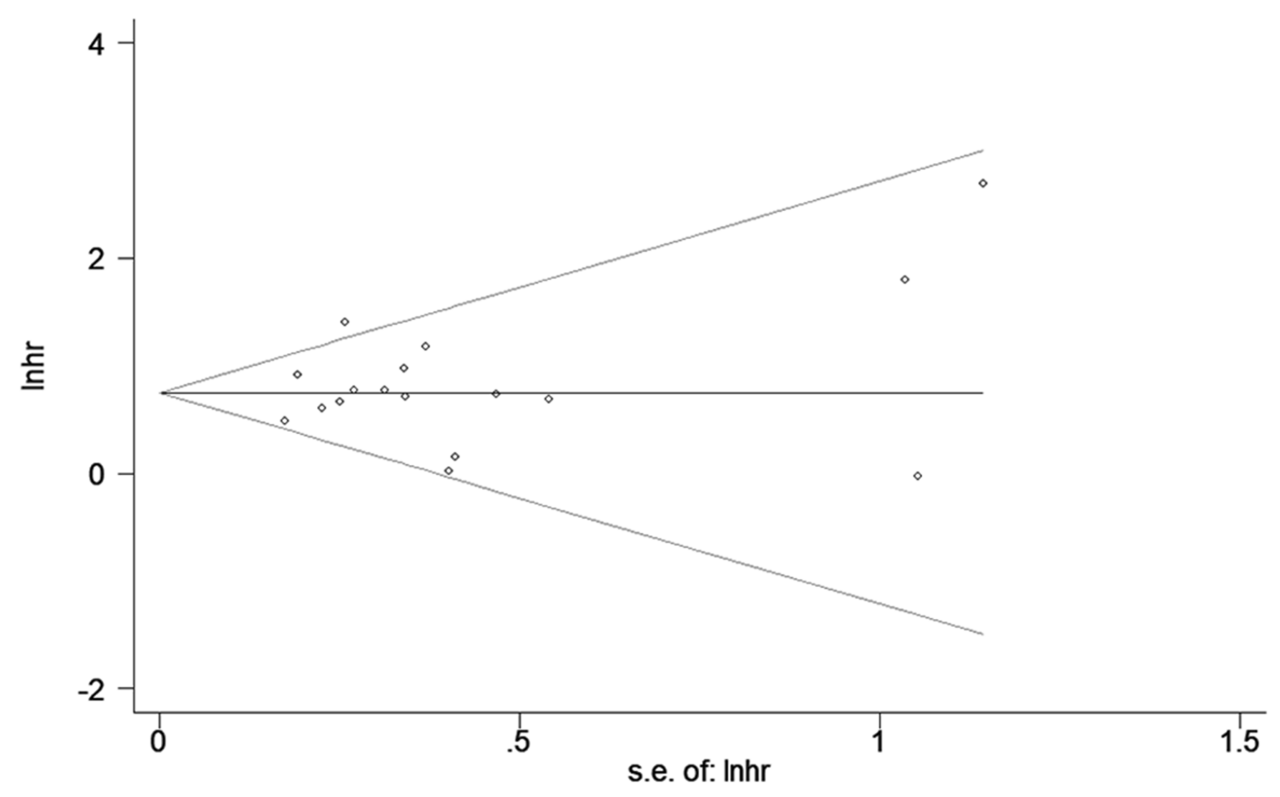

Figure 6 Begg's funnel plot of the association between GPS and overall survival.

treatment were included. A recently published meta-analysis concluded that elevated serum CRP levels were associated with poorer prognosis after pooling 5215 patients with nasopharyngeal carcinoma. ${ }^{33}$

Serum albumin is a factor not only reflecting the nutritional status, but also reflecting the inflammatory status which called the negative phase protein. Hypoalbuminemia could be commonly observed in cancer patients especially patients with gastric or esophageal cancer. Pretreatment hypoalbuminemia has been proved to be significantly associated with worse prognosis in several kinds of cancer. ${ }^{34,35}$

GPS is composed of CRP and serum albumin, which evaluates both the inflammatory response and nutritional status; and it has been proved to be a reliable factor in predicting survival of various kinds of cancers. Shim et al. ${ }^{36}$ argued in their meta-analysis that higher GPS was significantly associated with tumor progression and predict poorer survival in patients with renal cell carcinoma after pooling 9 studies. Li et al. ${ }^{37}$ demonstrated a significant relationship between elevated GPS and inferior OS in patients with hepatocellular carcinoma in their meta-analysis, and those patients with increased GPS tend to have shorter progression-free survival though it did not reach statistical significance. Dolan et al. ${ }^{38}$ proved in another meta-analysis that GPS was significantly associated with OS and CSS of operable cancer including esophageal cancer. Our results were in consistence with previous meta-analyses, making the results credible.
According to our meta-analysis, GPS could serve as a promising prognostic biomarker of esophageal cancer in predicting prognosis. McMillan ${ }^{39}$ reported that GPS may not only identify the risk of esophageal cancer but also provide a well-defined therapeutic target for future clinical treatment. Furthermore, we believed that patients with elevated pretreatment GPS should receive more active therapies like nonsteroidal anti-inflammatory drugs (NSAIDs) which were proved to have an apparent ability to reduce the risk of metastasis development in cancer patients by a recent meta-analysis. ${ }^{40}$ This may illustrate the great clinical significance of our research. However, these recommendations or opinions still need to be confirmed in future studies.

There are some limitations in our meta-analysis. First of all, some baseline characteristics such as the treatment, TNM stage and follow-up duration varied between studies. These confounding factors might lead to heterogeneity. Secondly, almost all the included studies were retrospective, which was susceptible to some biases. More welldesigned prospective studies are still needed to verify the prognostic value of GPS in esophageal cancer. Thirdly, the significant relationship between GPS and CSS was observed, but we failed to perform subgroup analysis to explore the source of high heterogeneity due to the shortage of related studies. Fourthly, the subgroup analysis based on the pathology type manifested the prognostic value of GPS in ESCC (HR $=1.87,95 \%$ CI: $1.55-2.26$, $p<0.001)$. However, we failed to explore the role of GPS 
in predicting survival of EAC patients because none of the included studies provided the data of the association between GPS and prognosis of EAC.

In conclusion, our meta-analysis demonstrated that pretreatment GPS was significantly associated with OS and CSS and could be regarded as an ideal factor in predicting the prognosis of patients with esophageal cancer. Large prospective cohort studies are warranted to verify our findings.

\section{Author contributions}

All authors contributed to data analysis, drafting or revising the article, gave final approval of the version to be published, and agree to be accountable for all aspects of the work.

\section{Disclosure}

The authors report no conflicts of interest in this work.

\section{References}

1. Chen W, Zheng R, Baade PD, et al. Cancer statistics in China, 2015. CA Cancer J Clin. 2016;66(2):115-132. doi:10.3322/caac.21338

2. Roxburgh CS, McMillan DC. Role of systemic inflammatory response in predicting survival in patients with primary operable cancer. Future Oncol. 2010;6(1):149-163. doi:10.2217/fon.09.136

3. Nakamura M, Iwahashi M, Nakamori M, et al. New prognostic score for the survival of patients with esophageal squamous cell carcinoma. Surg Today. 2014;44(5):875-883. doi:10.1007/s00595-013-0628-z

4. Liu JS, Huang Y, Yang X, Feng JF. A nomogram to predict prognostic values of various inflammatory biomarkers in patients with esophageal squamous cell carcinoma. Am J Cancer Res. 2015;5(7):2180-2189.

5. Liu DQ, Li FF, Jia WH. Cumulative scores based on plasma D-dimer and serum albumin levels predict survival in esophageal squamous cell carcinoma patients treated with transthoracic esophagectomy. Chin J Cancer. 2016;11(35):11. doi:10.1186/s40880-015-0062-2

6. Okuno T, Wakabayashi M, Kato K, et al. Esophageal stenosis and the Glasgow prognostic score as independent factors of poor prognosis for patients with locally advanced unresectable esophageal cancer treated with chemoradiotherapy (exploratory analysis of JCOG0303). Int J Clin Oncol. 2017;22(6):1042-1049. doi:10.1007/s10147-017-1154-6

7. Forrest LM, McMillan DC, McArdle CS, Angerson WJ, Dunlop DJ. Evaluation of cumulative prognostic scores based on the systemic inflammatory response in patients with inoperable non-small-cell lung cancer. $\mathrm{Br}$ J Cancer. 2003;89(6):1028-1030. doi:10.1038/sj.bjc.6601242

8. Nozoe T, Iguchi T, Egashira A, Adachi E, Matsukuma A, Ezaki T. Significance of modified Glasgow prognostic score as a useful indicator for prognosis of patients with gastric carcinoma. Am J Surg. 2011;201(2):186-191. doi:10.1016/j.amjsurg.2010.01.030

9. Ishizuka M, Kubota K, Kita J, Shimoda M, Kato M, Sawada T. Impact of an inflammation-based prognostic system on patients undergoing surgery for hepatocellular carcinoma: a retrospective study of 398 Japanese patients. Am J Surg. 2012;203(1):101-106. doi:10.1016/j.amjsurg.2010.09.030

10. Ishizuka M, Nagata $H$, Takagi K, Horie T, Kubota K. Inflammationbased prognostic score is a novel predictor of postoperative outcome in patients with colorectal cancer. Ann Surg. 2007;246(6):1047-1051. doi:10.1097/SLA.0b013e3181454171

11. Vashist YK, Loos J, Dedow J, et al. Glasgow prognostic score is a predictor of perioperative and long-term outcome in patients with only surgically treated esophageal cancer. Ann Surg Oncol. 2011;18 (4):1130-1138. doi:10.1245/s10434-010-1383-7
12. Tierney JF, Stewart LA, Ghersi D, Burdett S, Sydes MR. Practical methods for incorporating summary time-to-event data into metaanalysis. Trials. 2007;7(8):16. doi:10.1186/1745-6215-8-16

13. Higgins JP, Thompson SG, Deeks JJ, Altman DG. Measuring inconsistency in meta-nanalyses. BMJ. 2003;327(7414):557-560. doi:10.1136/bmj.327.7414.557

14. Duval S, Tweedie R. Trim and fll: a simple funnel-plot-based method of testing and adjusting for publication bias in meta-analysis. Biometrics. 2000;56(2):455-463. doi:10.1111/j.0006-341X.2000.00455.x

15. Moher D, Shamseer L, Clarke M, et al. Preferred reporting items for systematic review and meta-analysis protocols (PRISMA-P) 2015 statement. Syst Rev. 2015;4:1. doi:10.1186/2046-4053-4-1

16. Wang CY, Lee TF, Fang CH, Chou JH. Fuzzy logic-based prognostic score for outcome prediction in esophageal cancer. IEEE Trans Inf Technol Biomed. 2012;16(6):1224-1230. doi:10.1109/TITB.2012.2211374

17. Kimura J, Kunisaki C, Makino H, et al. Evaluation of the Glasgow prognostic score in patients receiving chemoradiotherapy for stage III and IV esophageal cancer. Dis Esophagus. 2016;29(8):1071-1080. doi:10.1111/dote. 12420

18. Hirahara N, Matsubara T, Hayashi H, Takai K, Fujii Y, Tajima Y. Impact of inflammation-based prognostic score on survival after curative thoracoscopic esophagectomy for esophageal cancer. Eur $J$ Surg Oncol. 2015;41(10):1308-1315. doi:10.1016/j.ejso.2015.07.008

19. Lindenmann J, Fink-Neuboeck N, Avian A, et al. Preoperative Glasgow prognostic score as additional independent prognostic parameter for patients with esophageal cancer after curative esophagectomy. Eur $J$ Surg Oncol. 2017;43(2):445-453. doi:10.1016/j.ejso.2016.10.015

20. Feng JF, Zhao Q, Chen QX. Prognostic significance of Glasgow prognostic score in patients undergoing esophagectomy for esophageal squamous cell carcinoma. Saudi J Gastroenterol. 2014;20 (1):48-53. doi:10.4103/1319-3767.126319

21. Toyokawa T, Kubo N, Tamura T, et al. The pretreatment Controlling nutritional status (CONUT) score is an independent prognostic factor in patients with resectable thoracic esophageal squamous cell carcinoma: results from a retrospective study. BMC Cancer. 2016;16:722. doi:10.1186/s12885-016-2696-0

22. Xu XL, Yu HQ, Hu W, Song Q, Mao WM. A novel inflammation-based prognostic score, the $\mathrm{C}$-reactive protein/albumin ratio predicts the prognosis of patients with operable esophageal squamous cell carcinoma. PLoS One. 2015;10(9):e0138657. doi:10.1371/journal.pone.0138657

23. Lindenmann J, Fink-Neuboeck N, Koesslbacher M, et al. The influence of elevated levels of $\mathrm{C}$-reactive protein and hypoalbuminemia on survival in patients with advanced inoperable esophageal cancer undergoing palliative treatment. J Surg Oncol. 2014;110(6):645-650. doi: $10.1002 /$ jso. 23711

24. Ohira M, Kubo N, Masuda G, et al. Glasgow prognostic score as a prognostic clinical marker in T4 esophageal squamous cell carcinoma. Anticancer Res. 2015;35(9):4897-4901.

25. Kobayashi T, Teruya M, Kishiki T, et al. Inflammation-based prognostic score, prior to neoadjuvant chemoradiotherapy, predicts postoperative outcome in patients with esophageal squamous cell carcinoma. Surgery. 2008;144(5):729-735. doi:10.1016/j.surg.2008.08.015

26. Matsuda S, Takeuchi H, Kawakubo H, et al. Cumulative prognostic scores based on plasma fibrinogen and serum albumin levels in esophageal cancer patients treated with transthoracic esophagectomy: comparison with the Glasgow prognostic score. Ann Surg Oncol. 2015;22(1):302-310. doi:10.1245/s10434-014-3857-5

27. Ma Q, Liu W, Jia R, et al. Inflammation-based prognostic system predicts postoperative survival of esophageal carcinoma patients with normal preoperative serum carcinoembryonic antigen and squamous cell carcinoma antigen levels. World J Surg Oncol. 2016;14:141. doi:10.1186/s12957-016-0878-5

28. Jomrich G, Paireder M, Gleiss A, Kristo I, Harpain L, Schoppmann SF. Comparison of inflammation-based prognostic scores in a cohort of patients with resectable esophageal cancer. Gastroenterol Res Pract. 2017;2017:1678584. 
29. Tan Z, Zhang M, Han Q, et al. A novel blood tool of cancer prognosis in esophageal squamous cell carcinoma: the fibrinogen/albumin ratio. $J$ Cancer. 2017;8(6):1025-1029. doi:10.7150/jca.16491

30. Yu X, Wen Y, Lin Y, et al. The value of preoperative Glasgow prognostic score and the $\mathrm{C}$-reactive protein to albumin ratio as prognostic factors for long-term survival in pathological T1N0 esophageal squamous cell carcinoma. J Cancer. 2018;9(5):807-815. doi:10.7150/jca.22755

31. Kunizaki M, Tominaga T, Wakata K, et al. Clinical significance of the C-reactive protein-to-albumin ratio for the prognosis of patients with esophageal squamous cell carcinoma. Mol Clin Oncol. 2018;8 (2):370-374. doi: $10.3892 /$ mco.2017.1527

32. Kitagawa H, Namikawa T, Munekage M, et al. Preoperative patientrelated factors associated with prognosis after esophagectomy for esophageal cancer. Esophagus. 2017;14(4):360-365. doi:10.1007/s10388-0170586-4

33. Fang $\mathrm{Y}, \mathrm{Xu} \mathrm{C}$, Wu $\mathrm{P}$, et al. Prognostic role of $\mathrm{C}$-reactive protein in patients with nasopharyngeal carcinoma: a meta-analysis and literature review. Medicine (Baltimore). 2017;96(45):e8463. doi:10.1097/ MD.0000000000008463

34. Lim WS, Roh JL, Kim SB, Choi SH, Nam SY, Kim SY. Pretreatment albumin level predicts survival in head and neck squamous cell carcinoma. Laryngoscope. 2017;127(12):E437-E442. doi:10.1002/lary.26691
35. Ayhan A, Günakan E, Alyazıcı İ, Haberal N, Altundağ Ö, Dursun P. The preoperative albumin level is an independent prognostic factor for optimally debulked epithelial ovarian cancer. Arch Gynecol Obstet. 2017;296(5):989-995. doi:10.1007/s00404-017-4511-9

36. Shim SR, Kim SJ, Kim SI, Cho DS. Prognostic value of the Glasgow prognostic score in renal cell carcinoma: a meta-analysis. World $J$ Urol. 2017;35(5):771-780. doi:10.1007/s00345-016-1940-1

37. Li MX, Bi XY, Li ZY, et al. Prognostic role of Glasgow prognostic score in patients with hepatocellular carcinoma: a systematic review and meta-analysis. Medicine (Baltimore). 2015;94(49):e2133. doi:10.1097/MD.0000000000000874

38. Dolan RD, Lim J, McSorley ST, Horgan PG, McMillan DC. The role of the systemic inflammatory response in predicting outcomes in patients with operable cancer: systematic review and meta-analysis. Sci Rep. 2017;7(1):16717. doi:10.1038/s41598-017-16955-5

39. McMillan DC. The systemic inflammation-based Glasgow prognostic score: a decade of experience in patients with cancer. Cancer Treat Rev. 2013;39(5):534-540. doi:10.1016/j.ctrv.2012.08.003

40. Zhao X, Xu Z, Li H. NSAIDs use and reduced metastasis in cancer patients: results from a meta-analysis. Sci Rep. 2017;7(1):1875. Epub 2017 May 14. doi:10.1038/s41598-017-01644-0

\section{Publish your work in this journal}

Cancer Management and Research is an international, peer-reviewed open access journal focusing on cancer research and the optimal use of preventative and integrated treatment interventions to achieve improved outcomes, enhanced survival and quality of life for the cancer patient.
The manuscript management system is completely online and includes a very quick and fair peer-review system, which is all easy to use. Visit http://www.dovepress.com/testimonials.php to read real quotes from published authors. 